pation on canton, town and school district levels altered the conditions for school funding. While this change increased the political will to invest in schooling, it also paved the way for new modes of funding. On both canton (1830s) and school district level (1860s), new taxes on income and/or property were introduced to meet the growing expenditure.

During the studied period, schooling seems to have occupied a unique position in local politics and economy. Though there were exceptions and backlashes, the leading elite/burghers/town dwellers generally displayed a remarkable readiness to invest in schooling by, for example, founding new types of schools or raising teachers' salaries. Even in times of cutbacks, schooling was usually spared. Aubry Kradolfer's study reveals variations in local priorities assigned to different needs, as well as different schools. Resources were primarily directed towards the burghers' grammar school, while spending on girls' and settler schools was more modest and usually made later than the corresponding investment in grammar schools.

The motives for this continuous and generous spending on schooling are fascinating. Schools were, already during this period of time, understood as a form of investment that would result in future economic gains. It was also expected that educated men would be better equipped to represent the interests of the town against or within the state. Upon reading this work, additional motives also emerges: schooling as a symbol of that already achieved, rather than a question of potential future gains. The element of manifestation seems especially apparent in the early reforms, celebrated by public ceremonies and completed by the renovation of the facade of the schoolhouse.

Aubry Kradolfer traces the evolution of local schooling through a web of political, economic and social conditions that dictates what is necessary, desirable or possible in educational matters. Needless to say, the study and presentation contain far greater detail and complexity than can be conveyed here. Her study belongs to a tradition in historical research that focuses on the local histories of schooling that preceded the establishment of national systems. In this context, the works of Peter Lindert and Nancy Beadie are also very important, as they serve as inspiration. Moreover, their findings, as noted in the concluding chapter, have parallels in those of the present study. Aubry Kradolfer's study aims at, and succeeds in, delivering a contribution to our understanding of the complex local beginnings of public schooling that is well worth reading.

Peter Bernhardsson

Uppsala University

Email:peter.bernhardsson@edu.uu.se

\section{Nancy Beadie \\ Education and the Creation of \\ Capital in the Early American \\ Republic}

Cambridge: Cambridge University Press

2010, 368 pp.

$B_{w}^{e}$ eadie's work is a valuable and, in many ways, a unique case study of schooling from the late eighteenth century until about 1840 in Lima, a small rural town in the Genesee River region of Upstate New York. The author offers a detailed description of the foundation of the Genesee Wesleyan Seminary in which she integrates educational history with political, religious, local, institutional and social history. Through this approach, Beadie succeeds in highlighting general questions about the role of education in society, while revealing problems associated with the established image of so-called state (public) schools.

Beadie demonstrates that, in Lima-a town with around 1,500 inhabitants-major joint efforts were made to provide children with educational opportunities. This was done, for example, by fund raising, student fees and through subscriptions. Beadie also shows that such voluntary efforts increased the demand for education in rural areas throughout this period. Beadie attributes special significance to religious networks that, according to her, contributed to economic development through the construction of new schools and improving educational opportunities at the local level.

Beadie works her way through this comprehensive and detailed history of schooling, placing it in the context of the early years of the republic and the transition to capitalism. Her analysis shows how the vol- 
untary contributions to schools and education in Lima interacted with the expanding market economy. Building and maintaining schools attracted capital that, in turn, promoted economic development. Beadie, however, emphasises the importance of social capital in this context. The people in Lima dared venture into capital-intensive projects - such as the building of a schoolhouse-owing to shared efforts and a sense of trust. According to Beadie, this activity produced a mobilisation of political capital, which interacted with other forms of capital, allowing them to mutually reinforce each other. In this way, economic development was promoted.

The strong emphasis of the relationship between the development of education and social and economic capital permeates the entire book. As a result, the traditional perspective focusing on relationship between education and politics is replaced by an inquiry into how the state acquired local school resources that were a result of voluntary efforts. Instead of analysing how education produced human capital, she focuses on how social capital was created, mobilised and transformed into political capital through schooling. This change of perspective is perhaps also Beadie's primary contribution to this field of research.

The study is burdened by the fact that the capital forms that are being discussed are not limited or properly demarcated. Beadie accounts for a large number of capital forms that are not defined. Consequently, capital may be identified in almost every relationship between individuals or organisations. The risk associated with this approach is that it makes it possible to discover capital even where the acknowledgement of the type of capital was low. This may in turn lead to the interpretation that capital was more evenly distributed than it actually was. Beadie writes explicitly that she chose a starting point where people are not categorised according to the social class. Instead of highlighting social, economic and political changes, she is trying to find the roots of school financing in social networks.

However, by failing to analyse social class, she leaves the question of whether the networks were shaped with the help of the societal positions of those people who formed the network. And if access to the social networks was determined by the so- cial class that these people belonged to, this would have impact on the analysis. In such a case, economic capital preceded both the building of the schools and the expansion of education. Since Beadie does not carry out a systematic analysis of the social structure of Lima, this issue remains a moot point.

Beadie's book is, without a doubt, a considerable contribution to the existent research. In stating this, I primarily refer to the extensive source material that she has based her study on, and her ability to move gracefully between various levels of analysis. Despite being a local case study, it addresses several issues that have bearing on a number of broader contexts. Thus, Beadie clearly demonstrates that she is an eminent scholar that is comfortable dealing not only with matters of educational history, but also with issues within the disciplines of history, economics and sociology.

Apart from this multidisciplinary approach, combining theoretical discussions with narratives of individual life stories is a hallmark of her study. For example, when Beadie presents insights into the market revolution of the late 1830s, she also describes the life of the teacher Clarissa Pengra. This is done seamlessly, as she never loses focus on the general level of her analysis. Yet, in doing so, she allows the reader to appreciate the humility of the individual experiences, which are not easily reduced to a part of the whole. In this way, Education and the Creation of Capital in the Early American Republic also becomes available to a much wider audience and will find interest beyond readers with a special interest in the history of education. It is thus very positive that the book was recently published as a paperback at a significantly lower price than the hardback.

In writing this book, Beadie's objectives were to explore the importance of education for economic development, as well as to highlight the human dimension in this process. The outcome is an excellent reinterpretation of how early American education can be understood.

Madeleine Michaëlsson Uppsala University

Email:madeleine.michaelsson@edu.uu.se 